\title{
Pediatric Glioma at the Optic Pathway and Thalamus
}

\author{
Eun Suk Park, M.D., Jun Bum Park, M.D., ${ }^{1}$ Young-Shin Ra, M.D. ${ }^{2}$ \\ Department of Neurosurgery, Ulsan University Hospital, University of Ulsan College of Medicine, Ulsan, Korea \\ Department of Neurological Surgery, ${ }^{2}$ Asan Medical Center, University of Ulsan College of Medicine, Seoul, Korea
}

Gliomas are the most common pediatric tumors of the central nervous system. In this review, we discuss the clinical features, treatment paradigms, and evolving concepts related to two types of pediatric gliomas affecting two main locations: the optic pathway and thalamus. In particular, we discuss recently revised pathologic classification, which adopting molecular parameter. We believe that our review contribute to the readers' better understanding of pediatric glioma because pediatric glioma differs in many ways from adult glioma according to the newest advances in molecular characterization of this tumor. A better understanding of current and evolving issues in pediatric glioma is needed to ensure effective management decision.

Key Words : Pediatrics · Brain neoplasms · Optic tract · Thalamus · Therapeutics · Treatment outcome.

\section{INTRODUCTION}

Gliomas are the most common central nervous system (CNS) tumors affecting pediatric patients ${ }^{60)}$. These tumors exhibit an extremely broad range of clinical behaviors. Their clinical features and courses can be affected by various factors, particularly location and pathology. The site of origin of a pediatric glioma within the $\mathrm{CNS}^{60)}$ can influence both the clinical presentation and the selection of surgical management. Various pathological subgroups of pediatric glioma, ranging from indolent (e.g., pilocytic astrocytoma) to aggressive tumors (e.g., glioblastoma), have been identified. The pathological characteristics of these subgroups should be considered during tumor management.

In the last decade, significant progress has been made in our understanding of the molecular biology underlying pediatric gliomas ${ }^{11,42,811}$. Notably, biologic subgroups characterized by dis- tinct molecular, pathologic, and clinical features have been identified, with the 2016 World Health Organization classification of tumors of the CNS adopting this concept ${ }^{55}$. In this review, we summarize the literature regarding pediatric gliomas located in the supratentorial deep midline in terms of both current concepts and evolving issues. We particularly focus on two main locations, the optic pathway and thalamus. Accordingly, our review is constructed around the two main themes of gliomas occurring in these locations.

\section{OPTIC PATHWAY GLIOMAS}

\section{Clinical features}

Optic pathway gliomas (OPGs) account for approximately $3-5 \%$ of pediatric brain tumors ${ }^{8,72}$. Approximately $75 \%$ of these

- Received : February 14, 2018 •Revised : March 15, 2018 •Accepted : March 29, 2018

- Address for reprints : Young-Shin Ra, M.D.

Department of Neurological Surgery, Asan Medical Center, University of Ulsan College of Medicine, 88 Olympic-ro 43-gil, Songpa-gu, Seoul 05505, Korea Tel : +82-2-3010-3550, Fax : +82-2-476-6738, E-mail : ysra@amc.seoul.kr

This is an Open Access article distributed under the terms of the Creative Commons Attribution Non-Commercial License (http://creativecommons.org/licenses/by-nc/4.0) which permits unrestricted non-commercial use, distribution, and reproduction in any medium, provided the original work is properly cited. 
tumors are diagnosed during the first decade of life, with $60 \%$ of patients receiving a diagnosis before the age of 5 years; the incidence does not differ by sex ${ }^{8,26)}$. OPGs can affect several anatomic regions along the optic pathway. The size and extent of the tumor influences the presentation, ranging from pure optic pathway gliomas (which are located in the optic nerve, optic chiasm, optic tracts and, less frequently, optic radiation) to larger exophytic tumors with extension into the hypothalamus, pituitary gland, third ventricle, and diencephalon ${ }^{8,26}$. Overall, $25 \%$ of OPGs are confined to the optic disc and nerve, whereas $40-75 \%$ involve the chiasm; of the latter, $33-60 \%$ are considered posterior lesions and also involve the hypothalamus or third ventricle ${ }^{8)}$.

Patients with OPGs may be asymptomatic or may present with variable symptoms, depending on the tumor location. The presenting symptoms are mainly ophthalmologic, including decreased or loss of vision, proptosis, strabismus, and nystagmus; these symptoms are often caused by a compromise of the optic pathways or diencephalon by either direct tumor invasion or compression ${ }^{4,26,36}$. Non-ophthalmologic symptoms may include endocrine dysfunction, cognitive problems, and behavioral disturbances ${ }^{4,26)}$. Endocrinologic symptoms such as precocious puberty and diencephalic syndrome indicate that an OPG affects the midline hypothalamic structures ${ }^{72}$. Symptoms of increased intracranial pressure (ICP) with hydrocephalus may also occur if the tumor obstructs the flow of cerebrospinal fluid through the third ventricle ${ }^{26)}$.

Incidentally discovered OPGs are typically associated with neurofibromatosis type 1 (NF-1). The reported incidence of NF-1 among patients with OPGs varies from 10 to $70 \%$; a majority of patients with these lesions are thought to have NF$1^{26,67,72)}$. OPGs associated with NF-1 are more often benign, may be multifocal and bilateral, and are usually found within the optic nerve $e^{31,45,82)}$. Notably, the presence of bilateral OPGs is a pathognomonic feature of NF-1 and was identified in 34.8\% of patients with the condition. Chiasmatic glioma is rarely associated with NF-1; however, such tumors often have a more aggressive course with diencephalic syndrome, and typically progress $^{31,45,82)}$.

Before making treatment decisions, as much information as possible must be obtained from imaging evaluations. The diagnoses of OPGs with typical imaging appearances can be confirmed using modern imaging modalities and protocols ${ }^{8,26}$. Radiologic evaluations of the tumor and surrounding struc- tures play a critical role in pre-surgical planning. Although both computed tomography and magnetic resonance imaging (MRI) are useful for radiologic evaluations, the latter is considered the mainstay of diagnostic imaging for pediatric $\mathrm{OPGs}^{26)}$. In such cases, typical MRI findings include the appearance of an iso- to hypointense lesion on T1-weighted images, hyperintensity on T2-weighted images, and homogeneous enhancement with Gd administration ${ }^{8,78)}$. These tumors are normally solid but may have cystic components; however, they rarely exhibit leptomeningeal spread, which tends to occur with more aggressive tumors such as pilomyxoid astrocytomas ${ }^{26,44,55)}$. Therefore, imaging can be used for tumor classification. Several researchers invented radiological classification using OPGs' anatomic location and their relation to the optic pathways ${ }^{21)}$. A recent report further proposed an MRI interpretation protocol intended to reduce intraobserver discrepancies ${ }^{47}$. We note, however, that prognostic validation is needed for classifications based solely on radiologic features, as these do not address surgical, genetic, and pathological factors.

Recently, newer MR imaging techniques such as MR spectroscopy (MRS), perfusion and diffusion-weighted MRI, and diffusion tensor imaging have been used for the pre- and posttreatment evaluation of OPGs. Reports have described the use of the former two techniques for tumor grading ${ }^{71,87)}$, whereas the latter has been used to assess the integrity of white matter tracts, including the optic radiations ${ }^{72,76)}$.

\section{Management}

Pathologically, OPGs are generally considered low grade ${ }^{8,26)}$. Juvenile pilocytic astrocytoma is the predominant histology and high-grade malignant pediatric OPGs are infrequently observed. Although clinical course predictions are difficult, as the natural courses range from stable disease to progression and even spontaneous regression ${ }^{34,59,65,76)}$. However, a large proportion of OPGs exhibit an indolent nature, particularly in the context of NF-1 ${ }^{59)}$. Still, tumor progression is typically observable within 2 years of diagnosis ${ }^{83}$. Despite the rarity of progression after the age of 12 years, some patients may lose their vision in adolescence. Therefore, these children should be subjected to careful vision monitoring until they reach adulthood.

Currently, the management options for OPGs include followed observation, chemotherapy, radiation therapy, and surgery. Given the pathologic and genetic diversity of OPGs, good long-term survival and functional results require a multidisci- 
plinary approach. Careful observation and timed intervention may be appropriate and reasonable options for these generally indolent tumors, particularly in the context of NF-1. However, patients presenting with symptoms and/or tumor progression on serial imaging scans should be considered candidates for appropriately selected interventions.

Because a significant portion of patients with OPGs also have NF-1, we consider it important to discuss the current recommendations for the screening of this population of patients. In 1997, the NIH NF-1 Optic Glioma Task Force outlined recommendations for the screening, follow-up, and treatment of OPG in children with $\mathrm{NF}-1^{53)}$; Listernick et al. ${ }^{52)}$ updated these initial recommendations in 2007. The updated recommendations strongly emphasize an annual screening examination, including visual acuity testing, confrontation visual field testing, color vision, pupillary reflexes, and an assessment of eyelids, ocular motility, and fundi, for children up to 8 years of age. Although no agreement has been reached regarding the time interval for the screening of patients older than 8 years, the guidelines recommend biennial screening until the age of 18 years until proven otherwise. Furthermore, the guidelines do not recommend using visual evoked potential as a screening tool. Regular ophthalmological examinations of NF-1 children with a known OPG at 3-month intervals are recommended during the first year, with larger intervals thereafter if progression is not evident.

OPGs require an individualized treatment approach based on combinations of surgery, chemotherapy, and/or radiotherapy. Accordingly, management decisions should be made through multidisciplinary team discussion after weighing the pros and cons of each treatment. For many years, the treatment of choice for OPG was surgical excision, which provided either a cure or prolonged stability ${ }^{32,84)}$. However, in some cases, such as NF-1 patients, it is discouraged because it inevitably causes blindness on the affected side, with the risk of bilateral loss of vision ${ }^{49}$. Furthermore, surgical biopsy has been supplanted by imagingassisted virtual diagnosis. Therefore, surgery should only be used in specific circumstances, such as the treatment of lesions causing significant unilateral visual compromise (often blindness) with evidence of extension into the chiasm, which thus threatens vision in the other eye. Here, prechiasmatic transection of the optic nerve can prevent tumor progression toward the chiasm, thereby maintaining vision in the contralateral eye ${ }^{9)}$. In such cases, thorough clinical and radiologic testing should be used to ensure that there is no involvement of the chiasm prior to surgical intervention. Other circumstances, including painful proptosis, corneal exposure, and disfigurement with severe visual loss in the involved eye, may also warrant surgical intervention $^{49,52,72)}$. Additionally, significant OPG growth can compress the third ventricle and thus cause hydrocephalus, necessitating lesion debulking to prevent further neurologic compromise ${ }^{4,26)}$.

Chemotherapy has become the predominant treatment modality for OPGs. Previously, this option was recommended as a first-line treatment for children under 7 years of age. Older children were initially offered radiotherapy ${ }^{8}$, as chemotherapy was shown to delay the need for radiotherapy in young children and thus allow time for neuropsychological development. However, the avoidance of radiation toxicity has led to the emergence of chemotherapy as the preferred first-line treatment, regardless of age, since $2000^{36,54)}$. Chemotherapy may stabilize or reduce the disease burden and thus prevent the need for neurosurgery and radiotherapy ${ }^{26,36,57)}$. Although no single ideal chemotherapeutic agent has been identified, the current standard chemotherapy regimen of vincristine and carboplatin, commonly known as the Packer regimen ${ }^{62,63)}$, was reported by Packer and colleagues to yield progression-free survival rates of $75 \%$ at 2 years and $68 \%$ at 3 years ${ }^{62)}$. Alternative chemotherapeutic regimens including thioguanine, procarbazine, lomustine, and vincristine with or without dibromodulcitol have yielded efficacies similar to that of the classical carboplatin and vincristine regimen ${ }^{3,68)}$. Temozolomide has also been shown to stabilize disease in more than $50 \%$ of patients without significant toxicity, and is considered an option for patients with progressive OPG in whom first-line therapy has failed ${ }^{33)}$. Additionally, a recent report described improved visual function in select patients treated with bevacizumab ${ }^{5}$. A systematic review of the effects of chemotherapy on visual outcomes found that less than $15 \%$ of cases demonstrated improvement, while $40 \%$ exhibited deterioration. Overall, the investigators concluded that chemotherapy did not improve the visual outcomes of children with OPGs ${ }^{58)}$. However, among NF-1 patients treated with chemotherapy, visual acuity remained stable or improved in $72 \%$ of patients and declined in $28 \%{ }^{24)}$. Researchers have also highlighted the importance of earlier treatment (i.e., treatment initiation $<5$ months from diagnosis) to prevent the occurrence of irreversible vision damage ${ }^{2,24)}$.

The role of radiotherapy in OPGs has changed considerably over the past decade. It used to be the treatment of choice, ahead of chemotherapy ${ }^{15)}$. Radiotherapy is an effective treatment for 
OPGs, with reported 10-year rates of progression-free survival as high as $90 \%{ }^{80}$. Conventional external beam radiotherapy for OPG is most commonly administered at total doses of 45-60 Gy in 1.6-2.0 Gy fractions ${ }^{27,80}$. However, its use has been limited by significant risks, including neuroendocrine dysfunction, and neurodevelopmental delays ${ }^{27,33}$. Patients with NF-1 are particularly at risk of secondary neoplasms following radiation ${ }^{77)}$. Radiation damage also increases the risks of a secondary exacerbation of visual loss, Moyamoya syndrome, and cerebro-occlusive disease $^{28}$. Approximately 3.5\% of all children receiving radiation therapy will develop Moyamoya syndrome; patients with NF-1 have a much higher risk of this condition, compared to the general population ${ }^{20)}$. Therefore, radiotherapy is now reserved for tumors refractory to chemotherapy and surgery.

Fractionated stereotactic radiotherapy, proton beam radiotherapy, and stereotactic radiosurgery have been evaluated as means of reducing the adverse effects of conventional radiotherapy. The former is highly efficacious, with a progression-free survival rate of $72 \%$ at 5 years ${ }^{18)}$. Proton and photon beam therapy, which administer lower doses of radiation to the temporal lobes and pituitary gland, have been tested in small series of patients with promising results ${ }^{51)}$. Finally, Gamma knife radiosurgery (single session) has been used to treat optic pathway and hypothalamic gliomas; in a recent case series, this modality yielded a progression-free survival rate of $83 \%$ at 3 years, and more than $80 \%$ of patients experienced stabilized or improved visual acuity ${ }^{22}$. Despite the efficacies of these new radiotherapy modalities, physicians should remain cautious about the potential for serious adverse effects.

\section{THALAMIC GLIOMAS}

\section{Clinical features}

Although thalamic gliomas are rare, accounting for $1-5 \%$ of pediatric intracranial tumors ${ }^{37,46,79)}$, the incidence of thalamic glioma is relatively high in children relative to adults $(1 \%)^{37}$. Pediatric patients are affected at a median age of $8-10$ years, without sex predilection ${ }^{29,37,79)}$. The duration of symptoms varies in children, although the mean value of 6 months ${ }^{37)}$ is longer than that in adults. However, a shorter symptom duration may portend a worse prognosis and may correspond to a higher pathologic grade.

Children with thalamic gliomas may present with a range of symptoms attributable to the deep locations of these tumors ${ }^{37,70)}$. The most common symptoms include an increased ICP, headache, lethargy, nausea, vomiting and, if left untreated, stupor and coma. Visual symptoms are present in as many as 50\% of cases. Motor deficits are common, whereas sensory disturbances and movement disorders are less common. In addition to the deep location, tumor effects on the structures surrounding the thalamus may lead to several symptom complexes. For example, hypothalamic involvement results in endocrinopathies, whereas mammillothalamic tract or fornix involvement can cause cognitive dysfunction and memory problems. Additionally, bilateral thalamic lesions manifest the characteristic but unusual presentation of personality changes, memory loss, confusion, hallucinations, hyperphagia, and bradyphrenia ${ }^{37}$.

Thalamic gliomas can be categorized by growth characteristics as focal, diffuse, or bilateral ${ }^{37}$. Focal tumors occur at very discrete locations within the thalamus and grow to expand beyond the anatomical boundaries into the surrounding white matter and/or ventricles (third and lateral). These tumors typically correspond to World Health Organization (WHO) grade I juvenile pilocytic astrocytoma ${ }^{12)}$, and can be further subclassified according to the brain-tumor interface or a cystic or noncystic component. In contrast, the diffuse type does not display a well-demarcated tumor interface and thus typically migrates beyond its anatomical boundaries. These tumors typically correspond to the WHO grade II-IV fibrillary type ${ }^{13)}$.

Bilateral-type thalamic gliomas merit a separate discussion. These tumors, which have an approximate incidence of $14 \%$, are presumed to have a de novo bilateral origin, like multifocal gliomas, and exhibit bilateral symmetry at the time of diagnosis ${ }^{79)}$. As in other reports, patients with bilateral thalamic glioma had a relatively shorter mean duration of symptoms (2.5 vs. 8.7 months for unilateral thalamic gliomas ${ }^{79)}$. Surprisingly, although biopsies of these lesions have indicated a lower histologic grade, the prognosis is much worse; in other words, these tumors have a malignant course despite the lower-grade histology ${ }^{3779)}$.

Radiologic features provide significant clues about the histology of and management options for thalamic gliomas. Advanced neuroimaging provides additional information about the metabolism and physiology of these lesions and thus contributes to diagnosis and follow-up ${ }^{10,46)}$. Similar to the clinical presentations, the imaging characteristics of these tumors vary depending on the grade of malignancy. Up to $20 \%$ of tumors are solid and cystic with calcification ${ }^{10)}$. Furthermore, although 
most malignant gliomas exhibit peritumoral edema, enhancement, and necrosis, these characteristics may be absent from some high-grade tumors, which may reduce the reliability of tumor classification and grading based on conventional imaging ${ }^{64)}$. Advanced MRI techniques, such as perfusion MRI and MRS, can provide additional information to support tumor classification. On perfusion MRI, low-grade tumors have a relatively low regional cerebral blood volume, compared to high-grade tumors $^{56)}$. On MRS, high-grade tumors such as glioblastoma exhibit a high choline peak with a low $\mathrm{N}$-acetylaspartate peak and high choline-to-creatine ratios. Additionally, elevated levels of lipid and lactate, which correlate with necrosis, help to differentiate glioblastomas from high-grade gliomas such as anaplastic astrocytoma ${ }^{10)}$.

\section{Management}

The treatment regimen for pediatric thalamic glioma has not been clearly defined. Clinicians previously favored a conservative approach comprising stereotactic biopsy and radiotherapy over radical resection, given the risks of postoperative morbidity and mortality ${ }^{16,25)}$. However, recent improvements in imaging modalities, neuronavigation systems, microsurgical techniques, and intraoperative electrophysiological monitoring have yielded clear anatomical pictures of these deeply seated lesions; therefore, radical resection of a selected subset of these tumors is associated with minimal morbidity and mortality ${ }^{14,37,50,74)}$. Generally, patients who have undergone total or subtotal resections of thalamic tumors experience improved outcomes and survival prognoses compared to those who do not undergo surgery $^{85)}$. Improved overall survival is associated with the extent of resection and can be achieved with minimal occurrences of morbidity and mortality ${ }^{85)}$.

Contrast-enhancing discrete lesions with well-defined boundaries and no involvement of the posterior limb of the internal capsule are best suited for radical resection ${ }^{74)}$. Various surgical approaches have been described for thalamic gliomas ${ }^{37,74,79)}$, although the position of the internal capsule relative to the tumor is a key factor when determining the approach. The optimal approach typically depends on the location of the tumor within the thalamus and the extent and relationship of the tumor to critical structures ${ }^{79)}$. Bilginer et al. ${ }^{7)}$ favor the anterior interhemispheric transcallosal approach for superior thalamic tumors and the posterior interhemispheric parasplenial approach for posterior thalamic tumors. Ozek and Türe ${ }^{61)}$ also recom- mend the interhemispheric transcallosal approach for patients with superior and anterior thalamic tumors. In contrast, Baroncini et al. ${ }^{6)}$ prefer the transcortical frontal approach for tumors in the superior thalamus. For large tumors in highly functional areas or areas with poorly defined boundaries, Puget et al. ${ }^{70)}$ recommend the staged excision of thalamic tumors. Tumors that cannot be resected safely should be investigated using biopsy sampling to exclude non-neoplastic pathological entities and direct future adjuvant therapies based on histological tumor types. Stereotactic or endoscopic biopsy should be considered in cases that may require only a tissue diagnosis or are otherwise appropriate (e.g., bilateral thalamic tumors) ${ }^{37)}$. For unilateral lesions with diagnostically ambiguous imaging findings, an imaging or endoscopically guided biopsy can establish a diagnosis and allow the identification of molecular markers before initiating an open approach ${ }^{37)}$.

Radiotherapy and chemotherapy should be reserved for patients with malignant thalamic lesions, multiple recurrent tumors, or residual disease ${ }^{37)}$. However, neither option is superior to complete resection, and both carry potential long-term adverse effects that are of significant concern in young children. Therefore, adjuvant therapies should not be considered without a histological diagnosis ${ }^{37)}$. For incompletely resected or progressive lesions, most centers administer a total radiation dose of 54 Gy administered over 30 fractions ${ }^{35,37,66)}$. However, many centers are switching to primary chemotherapy to avoid late irradiation effects such as endocrinopathies, vasculopathies, optic nerve damage, and loss of intellectual function. Therefore, reoperation should be offered, if feasible, to address a small residual, recurrent, or regrown low-grade glioma on serial imaging.

Currently, no standardized protocol exists for the chemotherapeutic treatment of low-grade gliomas. Generally, these lesions are treated with a combination of agents, although studies have reported varying levels of success with single agents ${ }^{35}$. However, a combination of vincristine and carboplatin and vinblastine monotherapy have been accepted as first-line adjuvant chemotherapy regimens ${ }^{35)}$. In contrast, the standard treatment for high-grade gliomas comprises surgery followed by radiotherapy. Although various combinations of chemotherapeutic agents have been tested, adult studies have led most pediatric neuro-oncology groups to adopt the combination of radiotherapy with concomitant and adjuvant temozolomide as the standard of care ${ }^{23,35)}$.

The factors influencing survival among patients with tha- 
lamic glioma include the tumor grade, extent of resection, adjuvant therapy, and symptom duration ${ }^{7,46,79)}$. Although children with low-grade gliomas have relatively good overall survival rates, the thalamic location portends a worse outcome, despite otherwise similar tumor biology ${ }^{37,85)}$. For high-grade gliomas, radical surgical resection remains the most important prognostic factor and should be considered unless severe morbidity is anticipated ${ }^{14,74,85)}$. Given their location, bilateral thalamic tumors are considered inoperable beyond diagnostic biopsy ${ }^{79}$, and have been reported to be less responsive to radiotherapy and chemotherapy treatment relative to unithalamic tumors ${ }^{37,79)}$. Consequently, bilateral thalamic tumors are associated with a poor outcome.

\section{CONTROVERSIAL AND EVOLVING ISSUES}

Several currently evolving issues in this field are notable. First, the 2016 World Health Organization Classification of Tumors of the CNS (Table 1) includes molecular parameters, as well as histology, in the definitions of CNS tumor entities ${ }^{55}$. This represents a significant break from the paradigm of the past century, wherein brain tumor classification was based largely on the concept of histogenesis; that is, tumors can be classified according to their microscopic similarities to different putative cells of origin and their presumed levels of differentiation ${ }^{55}$. Studies conducted over the past two decades have clarified the genetic basis of tumorigenesis in brain tumor entities, raising

Table. 1 The 2016 WHO classification with grade and ICD-O code in pediatric gliomas ${ }^{49)}$

\begin{tabular}{|c|c|c|}
\hline Tumor class & Grade & ICD-O code \\
\hline \multicolumn{3}{|l|}{ Diffuse astrocytoma and Oligodendroglial tumours } \\
\hline Diffuse astrocytoma, IDH-mutant & $\|$ & $9400 / 3$ \\
\hline Gemistocytic astrocytoma, IDH-mutant & & $9411 / 3$ \\
\hline Diffuse astrocytoma, IDH-wildtype & & $9400 / 3$ \\
\hline Diffuse astrocytoma, NOS & & $9400 / 3$ \\
\hline Anaplastic astrocytoma, IDH-mutant & III & $9401 / 3$ \\
\hline Anaplastic astrocytoma, IDH-wildtype & & $9401 / 3$ \\
\hline Anaplastic astrocytoma, NOS & & $9401 / 3$ \\
\hline Glioblastoma, IDH-wildtype & IV & $9440 / 3$ \\
\hline Giant cell glioblastoma & & $9441 / 3$ \\
\hline Gliosarcoma & & $9442 / 3$ \\
\hline Epithelioid glioblastoma & & $9440 / 3$ \\
\hline Glioblastoma, IDH-mutant & IV & $9445 / 3$ \\
\hline Glioblastoma, NOS & & $9440 / 3$ \\
\hline Diffuse midline glioma, H3 K27M-mutant & IV & $9385 / 3$ \\
\hline Oligodendroglioma, IDH-mutant and 1p/19q-codeleted & $\|$ & $9450 / 3$ \\
\hline Oligodendroglioma, NOS & & $9450 / 3$ \\
\hline Anaplastic oligodendroglioma, IDH-mutant and 1p/19q-codeleted & III & $9451 / 3$ \\
\hline Anaplastic oligodendroglioma, NOS & & $9451 / 3$ \\
\hline Oligoastrocytoma, NOS & & $9382 / 3$ \\
\hline Oligoastrocytoma, NOS & & $9382 / 3$ \\
\hline \multicolumn{3}{|l|}{ Other astrocytic tumours } \\
\hline Pilocytic astrocytoma & । & $9421 / 1$ \\
\hline Pilomyxoid astrocytoma & & $9425 / 3$ \\
\hline Subependymal giant cell astrocytoma & । & $9384 / 1$ \\
\hline Pleomorphic xanthoastrocytoma & $\|$ & $9424 / 3$ \\
\hline Anaplastic pleomorphic xanthoastrocytoma & III & $9424 / 3$ \\
\hline
\end{tabular}


Table. 1 Continued

\begin{tabular}{|c|c|c|}
\hline Tumor class & Grade & ICD-O code \\
\hline \multicolumn{3}{|l|}{ Other gliomas } \\
\hline Chordoid glioma of the third wentrice & $\|$ & $9444 / 1$ \\
\hline Angiocentric glioma & । & $9431 / 1$ \\
\hline Astroblastoma & & $9430 / 3$ \\
\hline \multicolumn{3}{|l|}{ Neuronal and mixed neuronal-glial tumours } \\
\hline Dysembryoplastic neuroepithelial tumour & I & $9413 / 0$ \\
\hline Gangliocytoma & । & $9492 / 0$ \\
\hline Ganglioglioma & 1 & $9505 / 1$ \\
\hline Anaplastic ganglioglioma & III & $9505 / 3$ \\
\hline Dysplastic cerebellar gangliocytoma (Lhermitte-Ducos disease) & । & $9493 / 0$ \\
\hline Desmoplastic infantile astrocytoma and ganglioglioma & । & $9412 / 1$ \\
\hline Papillary glioneuronal tumour & I & $9509 / 1$ \\
\hline Rosette-forming glioneuronal tumour & । & $9509 / 1$ \\
\hline \multicolumn{3}{|l|}{ Diffuse leptomeningeal glioneuronal tumour } \\
\hline Central neurocytoma & $\|$ & $9506 / 1$ \\
\hline Extraventricular neurocytoma & $\|$ & $9506 / 1$ \\
\hline Cerebellar liponeurocytoma & $\|$ & $9506 / 1$ \\
\hline Paraganglioma & & $8693 / 1$ \\
\hline
\end{tabular}

WHO : World Health Organization, ICD-O : the international classification of diseases for oncology, IDH : isocitrate dehydrogenase, NOS : not otherwise specified

the possibility that such an understanding may contribute to the classification of these tumors ${ }^{11,42,81)}$. Accordingly, the inclusion of molecular parameters in the 2016 WHO classification has led to significant changes in the diagnosis of glioma. Diffuse glioma now includes WHO grade II and grade III astrocytic tumors, grade II and III oligodendrogliomas, grade IV glioblastomas, and the related pediatric diffuse gliomas. Accordingly, this approach distinguishes diffuse gliomas from astrocytomas that have a more circumscribed growth pattern, lack IDH gene family alterations, and frequently harbor BRAF alterations (pilocytic astrocytoma, pleomorphic xanthastrocytoma) or TSC1/TSC2 mutations (subependymal giant cell astrocytoma). Accordingly, as diffuse astrocytoma and oligodendrogliomas are now considered nosologically more similar than diffuse astrocytoma and pilocytic astrocytoma, the family trees have been redrawn.

Moreover, despite histological similarities, the molecular characteristics of pediatric gliomas differ greatly from their adult counterparts, both in terms of mutation patterns and the prognostic implications of those mutations. These discoveries include the identification of recurrent mutations, fusion, and duplication events in the BRAF, FGFR1, MYB, and MYBL1 genes in pediatric low-grade gliomas, as well as mutations affecting histone components (H3F3A p.K27M or p. G34R/V) in pediatric high-grade gliomas ${ }^{11,42,73)}$. Adult low-grade gliomas are characterized by IDH1/2 mutations and ATRX mutations in astrocytic tumors and IDH1/2 mutations and 1p/19q codeletions in oligodendroglial tumors. TERT promoter mutations are also noted in low-grade gliomas and are mainly associated with oligodendrogliomas ${ }^{73}$.

Second, the concept of pediatric diffuse glioma has evolved. Previously, pediatric diffuse gliomas were grouped with their histologically similar adult counterparts, despite known differences in behavior. The group of tumors that primarily occur in children can be genetically characterized by K27M mutations in the histone $\mathrm{H} 3$ gene $\mathrm{H} 3 \mathrm{~F} 3 \mathrm{~A}$ (approximately $75 \%$ of cases) or, less commonly, in the related HIST1H3B gene (approximately $25 \%$ ) and exhibit clinically similar diffuse growth patterns and midline locations (e.g., thalamus, brain stem, and spinal cord). This newly defined entity is termed diffuse midline glioma, H3 K27M-mutant, and includes tumors previously referred to as diffuse intrinsic pontine glioma (DIPG) ${ }^{55)}$. 
Third, the grading of pilomyxoid astrocytoma has also evolved. In our experience, the pilomyxoid variant always follows a more aggressive course when compared to the suprasellar pilocytic astrocytoma, which has a more classic appearance. Accordingly, a suggestion was made to suppress the grading of pilomyxoid astrocytomas, which would be automatically assigned to WHO grade II until further studies have clarified their behavior.

These advances in pathological diagnosis have led to significant changes in routine clinical practice. For example, tumor genetic profiling has become an essential part of an evaluation. Along with this, the phenotypical and molecular identification of tumors can guide therapies directed against the effects of these mutations. At present, the mainstay of pediatric glioma therapy is surgical treatment, which may be curative for some low-grade gliomas when total resection is possible. However, when total resection is not possible or in cases of high-grade gliomas, the chances for progression or relapse are substantial. Although current adjuvant chemotherapy and radiotherapy are associated with relatively good overall tumor control in lowgrade gliomas, they have shown unsatisfactory results for highgrade gliomas. Even for low-grade gliomas, long-term treatment with adjuvant therapy is often associated with significant morbidity ${ }^{1}$. Thus, a more tailored and novel approach is needed for pediatric gliomas.

Another interesting discovery is the anatomic distribution of histone mutations in pediatric high-grade gliomas. K27M mutations are predominantly found in tumors arising in midline locations such as the thalamus, pons, and medulla oblongata. Histone H3.3 G34R or G34V mutations and BRAFV600E mutations are predominantly found in hemispheric tumors. Other gene alterations associated with histone gene mutations are also found in location-specific patterns. For example, ATRX/ DAXX mutations are associated with cortical G34R/V tumors ${ }^{40,81)}$. Furthermore, diffuse midline gliomas, H3 K27M-mutant (WHO grade IV) are a distinct group that was introduced in the recent revision of the WHO classification ${ }^{55}$. This group includes the tumors that were previously referred to as DIPG, as well as approximately $50-60 \%$ of diffuse gliomas that arise in the thalamus or spinal cord ${ }^{75,86)}$. Current treatment of these tumors does not include surgical resection due to their challenging location. However, several academic centers around the world have recently incorporated upfront biopsy for the identification of potential molecular alterations for targeted therapy ${ }^{69)}$. The surgically inaccessible location of these tumors, along with the fact that diffuse midline glioma H3 K27M-mutant is less chemosensitive and radiosensitive, results in a poor prognosis for affected children, who have a median survival time of 9-12 months and a survival rate of less than $10 \%$ two years after initial diagnosis, regardless of histological grade ${ }^{17,43)}$. In comparison, children with histone wild-type diffuse midline gliomas show significantly better overall survival times (mean, 4.5 years) ${ }^{43)}$.

Additionally, in patients with NF-1 associated OPGs, there is inactivation of the NF-1 tumor suppressor gene. The NF-1 gene located on chromosome 17q, which encodes neurofibromin, a negative regulator of RAS proto-oncogene ${ }^{30)}$. The NF-1 gene regulates cell differentiation, proliferation, and survival through mitogen activated protein kinase and mammalian target of rapamycin (mTOR) pathways ${ }^{41}$. Dysfunction of the NF-1 gene has been found to affect the mTOR pathway promoting cell survival, growth, and proliferation ${ }^{19)}$. And, it also activates RAS resulting in unregulated cell proliferation ${ }^{48}$. In the case of sporadic OPGs, it demonstrates a rearrangement in the kinase portion of the serine/threonin-protein kinase BRAF gene caused by fusion with KIAA1549 because of a duplication at $7 \mathrm{q} 34$ resulting in activation of BRAF $^{38,39)}$.

Several efforts are underway to develop novel therapeutic approaches for the treatment of pediatric gliomas, but significant challenges remain in translating these insights into clinical practice. Nonetheless, new molecular therapeutics are being evaluated for the treatment of pediatric gliomas, including crizotinib (a MET-fusion target), dabrafenib (a BRAF inhibitor), trametinib (a MEK inhibitor), nimotuzumab (an immunoglobulin G1 antibody that targets EGFR), crenolanib and dasatinib (a PDGFR inhibitor), and bevacizumab (an angiogenesis inhibitor $)^{11,40)}$. Many clinical trials investigating these targeted agents are still in the early phases, so the outcomes are pending. The success of targeted and personalized therapy not only requires these results, but also continued research into basic signaling mechanisms and the gene regulatory networks that drive the biology of pediatric brain tumors.

\section{CONFLICTS OF INTEREST}

No potential conflict of interest relevant to this article was reported. 


\section{INFORMED CONSENT}

This type of study does not require informed consent.

\section{- Acknowledgements}

This work was supported by the National Research Foundation of Korea (NRF) grant funded by the Korea government (MSIT) (No. 2017R1C1B5018208).

\section{References}

1. Armstrong GT, Conklin HM, Huang S, Srivastava D, Sanford R, Ellison DW, et al. : Survival and long-term health and cognitive outcomes after low-grade glioma. Neuro Oncol 13 : 223-234, 2011

2. Astrup $\mathrm{J}$ : Natural history and clinical management of optic pathway glioma. Br J Neurosurg 17 : 327-335, 2003

3. Ater JL, Zhou T, Holmes E, Mazewski CM, Booth TN, Freyer DR, et al. : Randomized study of two chemotherapy regimens for treatment of lowgrade glioma in young children: a report from the Children's Oncology Group. J Clin Oncol 30 : 2641-2647, 2012

4. Avery RA, Fisher MJ, Liu GT : Optic pathway gliomas. J Neuroophthalmol 31 : 269-278, 2011

5. Avery RA, Hwang El, Jakacki RI, Packer RJ : Marked recovery of vision in children with optic pathway gliomas treated with bevacizumab. JAMA Ophthalmol 132 : 111-114, 2014

6. Baroncini $M$, Vinchon $M$, Minéo JF, Pichon $F$, Francke JP, Dhellemmes $P$ : Surgical resection of thalamic tumors in children: approaches and clinical results. Childs Nerv Syst 23 : 753-760, 2007

7. Bilginer B, Narin F, Işıkay I, Oguz KK, Söylemezoglu F, Akalan N : Thalamic tumors in children. Childs Nerv Syst 30 : 1493-1498, 2014

8. Binning MJ, Liu JK, Kestle JR, Brockmeyer DL, Walker ML : Optic pathway gliomas: a review. Neurosurg Focus 23 : E2, 2007

9. Borghei-Razavi $H$, Shibao $S$, Schick $U$ : Prechiasmatic transection of the optic nerve in optic nerve glioma: technical description and surgical outcome. Neurosurg Rev 40 : 135-141, 2017

10. Borja MJ, Plaza MJ, Altman N, Saigal G : Conventional and advanced MRI features of pediatric intracranial tumors: supratentorial tumors. AJR Am J Roentgenol 200 : W483-W503, 2013

11. Braunstein $S$, Raleigh $D$, Bindra R, Mueller $S$, Haas-Kogan D : Pediatric high-grade glioma: current molecular landscape and therapeutic approaches. J Neurooncol 134 : 541-549, 2017

12. Broadway SJ, Ogg RJ, Scoggins MA, Sanford R, Patay Z, Boop FA : Surgical management of tumors producing the thalamopeduncular syndrome of childhood. J Neurosurg Pediatr 7 : 589-595, 2011

13. Burger PC, Cohen KJ, Rosenblum MK, Tihan T : Pathology of diencephalic astrocytomas. Pediatr Neurosurg 32 : 214-219, 2000

14. Cao L, Li C, Zhang Y, Gui S : Surgical resection of unilateral thalamic tumors in adults: approaches and outcomes. BMC Neurol 15 : 229, 2015
15. Cappelli C, Grill J, Raquin M, Pierre-Kahn A, Lellouch-Tubiana A, TerrierLacombe MJ, et al. : Long-term follow up of 69 patients treated for optic pathway tumours before the chemotherapy era. Arch Dis Child 79 : 334-338, 1998

16. Cheek WR, Taveras JM : Thalamic tumors. J Neurosurg 24 : 505-513, 1966

17. Cohen KJ, Pollack IF, Zhou T, Buxton A, Holmes EJ, Burger PC, et al. : Temozolomide in the treatment of high-grade gliomas in children: a report from the Children's Oncology Group. Neuro Oncol 13 : 317-323, 2011

18. Combs SE, Schulz-Ertner D, Moschos D, Thilmann C, Huber PE, Debus I : Fractionated stereotactic radiotherapy of optic pathway gliomas: tolerance and long-term outcome. Int J Radiat Oncol Biol Phys 62 : 814819, 2005

19. Dasgupta B, Yi Y, Chen DY, Weber JD, Gutmann DH : Proteomic analysis reveals hyperactivation of the mammalian target of rapamycin pathway in neurofibromatosis 1-associated human and mouse brain tumors. Cancer Res 65 : 2755-2760, 2005

20. Desai SS, Paulino AC, Mai WY, Teh BS : Radiation-induced moyamoya syndrome. Int J Radiat Oncol Biol Phys 65 : 1222-1227, 2006

21. Dodge HW Jr, Love JG, Craig WM, Dockerty MB, Kearns TP, Holman CB, et al. : Gliomas of the optic nerves. AMA Arch Neurol Psychiatry 79 : 607-621, 1958

22. El-Shehaby AM, Reda WA, Abdel Karim KM, Emad Eldin RM, Nabeel AM : Single-session Gamma knife radiosurgery for optic pathway/hypothalamic gliomas. J Neurosurg 125(1 Suppl) : 50-57, 2016

23. Finlay $\mathrm{JL}$, Zacharoulis $S$ : The treatment of high grade gliomas and diffuse intrinsic pontine tumors of childhood and adolescence: a historical-and futuristic-perspective. J Neurooncol 75 : 253-266, 2005

24. Fisher MJ, Loguidice M, Gutmann DH, Listernick R, Ferner RE, Ullrich NJ, et al. : Visual outcomes in children with neurofibromatosis type 1-associated optic pathway glioma following chemotherapy: a multicenter retrospective analysis. Neuro Oncol 14 : 790-797, 2012

25. Franzini A, Leocata F, Cajola L, Servello D, Allegranza A, Broggi G : Lowgrade glial tumors in basal ganglia and thalamus: natural history and biological reappraisal. Neurosurgery 35 : 817-820; discussion 820-821, 1994

26. Goodden JMC : Optic Pathway Hypothalamic Glioma in Winn HR (ed) : Youmans and Winn Neurological Surgery, ed 7th. Philadelphia : Elsevier, 2016, pp1660-1667

27. Grabenbauer GG, Schuchardt U, Buchfelder M, Rödel CM, Gusek G, Marx $\mathrm{M}$, et al. : Radiation therapy of optico-hypothalamic gliomas (OHG)-radiographic response, vision and late toxicity. Radiother Oncol 54 : 239-245, 2000

28. Grill J, Couanet D, Cappelli C, Habrand JL, Rodriguez D, Sainte-Rose C, et al. : Radiation-induced cerebral vasculopathy in children with neurofibromatosis and optic pathway glioma. Ann Neurol 45 : 393-396, 1999

29. Gupta A, Shaller N, McFadden KA : Pediatric thalamic gliomas: an updated review. Arch Pathol Lab Med 141 : 1316-1323, 2017

30. Gutmann DH, Donahoe J, Brown T, James CD, Perry A : Loss of neurofibromatosis 1 (NF1) gene expression in NF1-associated pilocytic astrocytomas. Neuropathol Appl Neurobiol 26 : 361-367, 2000 
31. Hoffman HJ, Humphreys RP, Drake JM, Rutka JT, Becker LE, Jenkin D, et al. : Optic pathway/hypothalamic gliomas: a dilemma in management. Pediatr Neurosurg 19 : 186-195, 1993

32. Hoffman HJ, Soloniuk DS, Humphreys RP, Drake JM, Becker LE, De Lima BO, et al. : Management and outcome of low-grade astrocytomas of the midline in children: a retrospective review. Neurosurgery 33 : 964971, 1993

33. Horwich A, Bloom HJ : Optic gliomas: radiation therapy and prognosis. Int J Radiat Oncol Biol Phys 11 : 1067-1079, 1985

34. Hoyt WF, Baghdassarian SA : Optic glioma of childhood. Natural history and rationale for conservative management. Br J Ophthalmol 53 : 793-798, 1969

35. Hummel TR, Chow LM, Fouladi M, Franz D : Pharmacotherapeutic management of pediatric gliomas: current and upcoming strategies. Paediatr Drugs $15: 29-42,2013$

36. Jahraus CD, Tarbell NJ : Optic pathway gliomas. Pediatr Blood Cancer $46: 586-596,2006$

37. Jeelani ODP : Thalamic Tumors in Winn HR (ed) : Youmans and Winn Neurological Surgery, ed 7th. Philadelphia : Elsevier, 2016, pp16691676

38. Jones DT, Kocialkowski S, Liu L, Pearson DM, Ichimura K, Collins VP : Oncogenic RAF1 rearrangement and a novel BRAF mutation as alternatives to KIAA1549:BRAF fusion in activating the MAPK pathway in pilocytic astrocytoma. Oncogene 28 : 2119-2123, 2009

39. Jones DT, Kocialkowski S, Liu L, Pearson DM, Bäcklund LM, Ichimura K, et al. : Tandem duplication producing a novel oncogenic BRAF fusion gene defines the majority of pilocytic astrocytomas. Cancer Res 68 : 8673 8677,2008

40. Juratli TA, Qin N, Cahill DP, Filbin MG : Molecular pathogenesis and therapeutic implications in pediatric high-grade gliomas. Pharmacol Ther $182: 70-79,2018$

41. Khatua S, Gutmann DH, Packer RJ : Neurofibromatosis type 1 and optic pathway glioma: Molecular interplay and therapeutic insights. Pediatr Blood Cancer 65 : 2018

42. Khatua $S$, Wang J, Rajaram V : Review of low-grade gliomas in children-evolving molecular era and therapeutic insights. Childs Nerv Syst 31 : 643-652, 2015

43. Khuong-Quang DA, Buczkowicz P, Rakopoulos P, Liu XY, Fontebasso AM, Bouffet $E$, et al. : K27M mutation in histone H3.3 defines clinically and biologically distinct subgroups of pediatric diffuse intrinsic pontine gliomas. Acta Neuropathol 124 : 439-447, 2012

44. Komotar RJ, Mocco J, Carson BS, Sughrue ME, Zacharia BE, Sisti AC, et al. : Pilomyxoid astrocytoma: a review. MedGenMed 6 : 42, 2004

45. Kornreich L, Blaser S, Schwarz M, Shuper A, Vishne TH, Cohen IJ, et al. : Optic pathway glioma: correlation of imaging findings with the presence of neurofibromatosis. AJNR Am J Neuroradiol 22 : 1963-1969, 2001

46. Kramm CM, Butenhoff S, Rausche U, Warmuth-Metz M, Kortmann RD, Pietsch T, et al. : Thalamic high-grade gliomas in children: a distinct clinical subset? Neuro Oncol 13 : 680-689, 2011

47. Lambron J, Rakotonjanahary J, Loisel D, Frampas E, De Carli E, Delion M, et al. : Can we improve accuracy and reliability of MRI interpretation in children with optic pathway glioma? Proposal for a reproducible imaging classification. Neuroradiology 58 : 197-208, 2016

48. Lau N, Feldkamp MM, Roncari L, Loehr AH, Shannon P, Gutmann DH, et al. : Loss of neurofibromin is associated with activation of RAS/MAPK and PI3-K/AKT signaling in a neurofibromatosis 1 astrocytoma. J Neuropathol Exp Neurol 59 : 759-767, 2000

49. Lee $A G$ : Neuroophthalmological management of optic pathway gliomas. Neurosurg Focus 23 : E1, 2007

50. Lee RP, Foster KA, Lillard JC, Klimo P Jr, Ellison DW, Orr B, et al. : Surgical and molecular considerations in the treatment of pediatric thalamopeduncular tumors. J Neurosurg Pediatr 20 : 247-255, 2017

51. Leroy R, Benahmed N, Hulstaert F, Van Damme N, De Ruysscher D : Proton therapy in children: a systematic review of clinical effectiveness in 15 pediatric cancers. Int J Radiat Oncol Biol Phys 95 : 267-278, 2016

52. Listernick R, Ferner RE, Liu GT, Gutmann DH : Optic pathway gliomas in neurofibromatosis-1: controversies and recommendations. Ann Neurol 61 : 189-198, 2007

53. Listernick R, Louis DN, Packer RJ, Gutmann DH : Optic pathway gliomas in children with neurofibromatosis 1: consensus statement from the NF1 optic pathway glioma task force. Ann Neurol 41 : 143-149, 1997

54. Liu GT : Optic gliomas of the anterior visual pathway. Curr Opin Ophthalmol $17: 427-431,2006$

55. Louis DN, Perry A, Reifenberger G, von Deimling A, Figarella-Branger D, Cavenee WK, et al. : The 2016 world health organization classification of tumors of the central nervous system: a summary. Acta Neuropathol $131: 803-820,2016$

56. Maia AC Jr, Malheiros SM, da Rocha AJ, da Silva CJ, Gabbai AA, Ferraz $F A$, et al. : MR cerebral blood volume maps correlated with vascular endothelial growth factor expression and tumor grade in nonenhancing gliomas. AJNR Am J Neuroradiol 26 : 777-783, 2005

57. Massimi L, Tufo T, Di Rocco C : Management of optic-hypothalamic gliomas in children: still a challenging problem. Expert Rev Anticancer Ther 7 : 1591-1610, 2007

58. Moreno L, Bautista F, Ashley S, Duncan C, Zacharoulis S : Does chemotherapy affect the visual outcome in children with optic pathway glioma? a systematic review of the evidence. Eur J Cancer 46 : 2253-2259, 2010

59. Opocher E, Kremer LC, Da Dalt L, van de Wetering MD, Viscardi E, Caron $\mathrm{HN}$, et al. : Prognostic factors for progression of childhood optic pathway glioma: a systematic review. Eur J Cancer 42 : 1807-1816, 2006

60. Ostrom QT, Gittleman H, Xu J, Kromer C, Wolinsky Y, Kruchko C, et al. : CBTRUS statistical report: primary brain and other central nervous system tumors diagnosed in the United States in 2009-2013. Neuro Oncol 18 : v1-v75, 2016

61. Ozek MM, Türe U : Surgical approach to thalamic tumors. Childs Nerv Syst $18: 450-456,2002$

62. Packer RJ, Ater J, Allen J, Phillips P, Geyer R, Nicholson HS, et al. : Carboplatin and vincristine chemotherapy for children with newly diagnosed progressive low-grade gliomas. J Neurosurg 86 : 747-754, 1997

63. Packer RJ, Lange B, Ater J, Nicholson HS, Allen J, Walker R, et al. : Carboplatin and vincristine for recurrent and newly diagnosed low-grade gliomas of childhood. J Clin Oncol 11 : 850-856, 1993 
64. Panigrahy $A$, Blüml $S$ : Neuroimaging of pediatric brain tumors: from basic to advanced magnetic resonance imaging (MRI). J Child Neurol 24 : 1343-1365, 2009

65. Parsa CF, Hoyt CS, Lesser RL, Weinstein JM, Strother CM, Muci-Mendoza $R$, et al. : Spontaneous regression of optic gliomas: thirteen cases documented by serial neuroimaging. Arch Ophthalmol 119 : 516-529, 2001

66. Pollack IF, Claassen D, al-Shboul Q, Janosky JE, Deutsch M : Low-grade gliomas of the cerebral hemispheres in children: an analysis of 71 cases. J Neurosurg 82 : 536-547, 1995

67. Prada CE, Hufnagel RB, Hummel TR, Lovell AM, Hopkin RJ, Saal HM, et al. : The use of magnetic resonance imaging screening for optic pathway gliomas in children with neurofibromatosis type 1. J Pediatr $167: 851-$ 856.e1, 2015

68. Prados MD, Edwards MS, Rabbitt J, Lamborn K, Davis RL, Levin VA : Treatment of pediatric low-grade gliomas with a nitrosourea-based multiagent chemotherapy regimen. J Neurooncol 32 : 235-241, 1997

69. Puget S, Beccaria K, Blauwblomme T, Roujeau T, James S, Grill J, et al. : Biopsy in a series of 130 pediatric diffuse intrinsic pontine gliomas. Childs Nerv Syst 31 : 1773-1780, 2015

70. Puget S, Crimmins DW, Garnett MR, Grill J, Oliveira R, Boddaert N, et al. : Thalamic tumors in children: a reappraisal. J Neurosurg 106 : 354-362, 2007

71. Pungavkar SA, Lawande MA, Patkar DP, Agrawal NV, Gadani S : Bilateral optic pathway glioma with intracranial calcification: magnetic resonance imaging and magnetic resonance spectroscopy findings. Australas Radiol 49 : 489-492, 2005

72. Rasool N, Odel JG, Kazim M : Optic pathway glioma of childhood. Curr Opin Ophthalmol $28: 289-295,2017$

73. Rodriguez FJ, Vizcaino MA, Lin MT : Recent advances on the molecular pathology of glial neoplasms in children and adults. J Mol Diagn 18 : 620-634, 2016

74. Sai Kiran NA, Thakar S, Dadlani R, Mohan D, Furtado SV, Ghosal N, et al. : Surgical management of thalamic gliomas: case selection, technical considerations, and review of literature. Neurosurg Rev 36 : 383-393, 2013

75. Schwartzentruber J, Korshunov A, Liu XY, Jones DT, Pfaff E, Jacob K, et al. : Driver mutations in histone $\mathrm{H} 3.3$ and chromatin remodelling genes in paediatric glioblastoma. Nature 482 : 226-231, 2012

76. Shapey J, Danesh-Meyer HV, Kaye AH : Diagnosis and management of optic nerve glioma. J Clin Neurosci 18 : 1585-1591, 2011

77. Sharif S, Ferner R, Birch JM, Gillespie JE, Gattamaneni HR, Baser ME, et al. : Second primary tumors in neurofibromatosis 1 patients treated for optic glioma: substantial risks after radiotherapy. J Clin Oncol 24 : 2570 2575, 2006

78. Shen TT, Sakai O, Curtin HD, Rizzo JF 3rd : Magnetic resonance imaging of primary anterior visual pathway tumors. Int Ophthalmol Clin 41 : 171-180, 2001

79. Steinbok P, Gopalakrishnan CV, Hengel AR, Vitali AM, Poskitt K, Hawkins $C$, et al. : Pediatric thalamic tumors in the MRI era: a Canadian perspective. Childs Nerv Syst 32 : 269-280, 2016

80. Stieber VW : Radiation therapy for visual pathway tumors. J Neuroophthalmol $28: 222-230,2008$

81. Sturm D, Pfister SM, Jones DTW : Pediatric gliomas: current concepts on diagnosis, biology, and clinical management. J Clin Oncol 35 : 2370 2377, 2017

82. Suárez JC, Viano JC, Zunino S, Herrera EJ, Gomez J, Tramunt B, et al. : Management of child optic pathway gliomas: new therapeutical option. Childs Nerv Syst 22 : 679-684, 2006

83. Sylvester $C L$, Drohan $L A$, Sergott $R C$ : Optic-nerve gliomas, chiasmal gliomas and neurofibromatosis type 1. Curr Opin Ophthalmol $17:$ 7-11, 2006

84. Wisoff $J H$, Abbott $R$, Epstein $F$ : Surgical management of exophytic chiasmatic-hypothalamic tumors of childhood. J Neurosurg $73: 661-667$, 1990

85. Wong TT, Chen HH, Liang ML, Hsieh KL, Yang YS, Ho DM, et al. : Clinical considerations and surgical approaches for low-grade gliomas in deep hemispheric locations: thalamic lesions. Childs Nerv Syst 32 : 1895-1906, 2016

86. Wu G, Broniscer A, McEachron TA, Lu C, Paugh BS, Becksfort J, et al. : Somatic histone $\mathrm{H} 3$ alterations in pediatric diffuse intrinsic pontine gliomas and non-brainstem glioblastomas. Nat Genet 44 : 251-253, 2012

87. Yeom KW, Lober RM, Andre JB, Fisher PG, Barnes PD, Edwards MS, et al. : Prognostic role for diffusion-weighted imaging of pediatric optic pathway glioma. J Neurooncol 113 : 479-483, 2013 